Regular Article

\title{
Chemically heterogeneous carbon dots enhanced cholesterol detection by MALDI TOF mass spectrometry
}

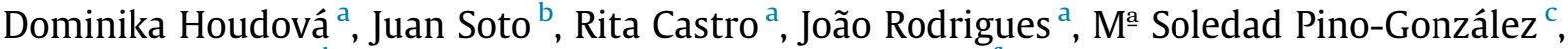 \\ Marijana Petković ${ }^{\mathrm{d}, *}$, Teresa J Bandosz ${ }^{\mathrm{e}, *}$, Manuel Algarra ${ }^{\mathrm{f}, *}$ \\ ${ }^{a}$ CQM-Centro de Química da Madeira, Universidade da Madeira, Campus da Penteada, 9020-105 Funchal, Portugal \\ ${ }^{\mathrm{b}}$ Department of Physical Chemistry. Faculty of Science, University of Málaga. Campus de Teatinos s/n, 29071 Malaga, Spain \\ ${ }^{\mathrm{c}}$ Department of Organic Chemistry. Faculty of Science, University of Málaga. Campus de Teatinos s/n, 29071 Málaga, Spain \\ ${ }^{\mathrm{d}}$ VINČA Institute of Nuclear Sciences-National Institute of the Republic of Serbia, University of Belgrade, Belgrade, Serbia \\ ${ }^{\mathrm{e}}$ Department of Chemistry and Biochemistry, The City College of New York, 160 Convent Ave, New York, NY, 10031, USA \\ ${ }^{\mathrm{f}}$ Department of Inorganic Chemistry. Faculty of Science, University of Málaga. Campus de Teatinos s/n, 29071 Málaga, Spain
}

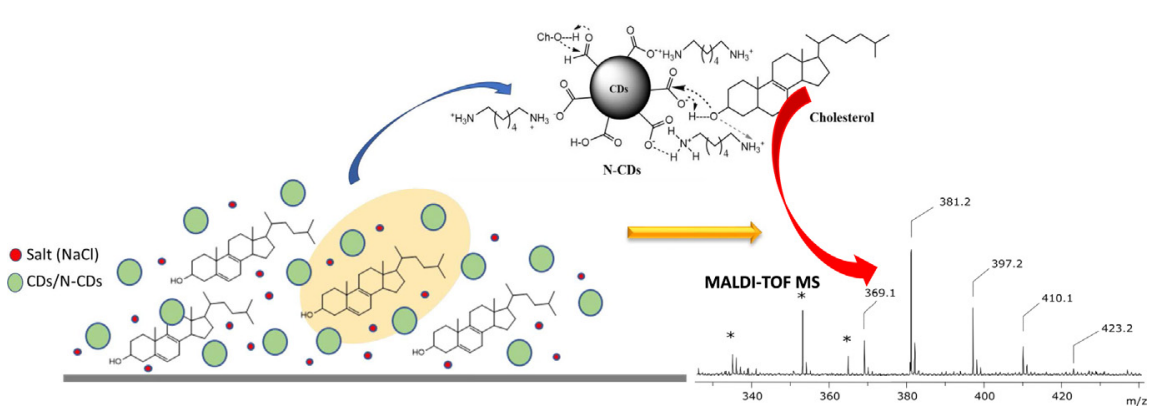

\section{A R T I C L E I N F O}

\section{Article history:}

Received 4 January 2021

Revised 1 February 2021

Accepted 2 February 2021

Available online 7 February 2021

\section{Keywords:}

Cholesterol

MALDI TOF

Carbon dots

$N$-doped Carbon dots

DFT calculations

\section{A B S T R A C T}

A binary system composed of carbon dots (CDs) and $N$-doped CDs ( $N$-CDs) embedded in an organic matrix was used for the analysis of cholesterol by MALDI (matrix-assisted laser desorption and ionization timeof-flight) mass spectrometry, as a model for detection of small, biologically relevant molecules. The results showed that both $\mathrm{CDs}$ are sensitive to the cholesterol and can be used either alone or in a binary system with 2,5-dihydroxybenzoic acid (DHB) to enhance the detection process. It was found that both $\mathrm{COOH}$ and $\mathrm{NH}_{2}$ groups on CDs surface contributed to the enhancement in the cholesterol detection by MALDI mass spectrometry in the presence of inorganic cations. Nevertheless, in the presence of $\mathrm{NaCl}$, $\mathrm{N}$-CDs led to a better reproducibility of results. It was due to the coexistence of positive and negative charge on $\mathrm{N}$-CDs surface that led to a homogeneous analyte/substrate distribution, which is an important detection parameter. The enhancing effect of carbon dots was linked to a negative Gibbs energy of the complex formation between $\mathrm{CDs}, \mathrm{Na}^{+}$, cholesterol and $\mathrm{DHB}$, and it was supported by theoretical calculations. Moreover, upon the addition of $\mathrm{CDs} / \mathrm{N}-\mathrm{CDs}$, such features as a low ionization potential, vertical excitation, dipole moment and oscillator strength positively affected the cholesterol detection by MALDI in the presence of $\mathrm{Na}^{+}$.

(c) 2021 Elsevier Inc. All rights reserved.

\footnotetext{
* Corresponding authors.

E-mail addresses: marijanapetkovic@vin.bg.ac.rs (M. Petković), tbandosz@ccny.cuny.edu (T.J Bandosz), malgarra@uma.es (M. Algarra).
} 


\section{Introduction}

A matrix-assisted laser desorption and ionization time-of-flight mass spectrometry (MALDI TOF MS) is a highly sensitive mass spectrometry method used a fast detection of a broad spectrum of (bio)molecules [1]. The method utilizes a laser, which emits in a UV or IR range, for the desorption and ionization. Because it does not induce a high extent of fragmentation, this method is considered as a soft ionization approach [2].

In MALDI, an analyte is usually mixed with an organic matrix and then both co-crystallize upon a solvent evaporation [3], leaving a solid mixture on a MALDI plate of analysis. Various organic compounds have been used as matrices. Examples are 1) aromatic compounds that absorb in the laser emission region, such as benzoic acid or cinnamic acid derivatives, 2) liquid crystals, such as organic ammonium salts (butyl ammonium salts), which are used for a soft ionization of labile analytes [4,5] and 3) inorganic materials such as graphite or metal-oxide nanoparticles [6,7]. The matrix should be selected based on a high signal-to-noise $(\mathrm{S} / \mathrm{N})$ ratio of an analyte signal. Other important features are a high resolution of an acquired spectra, low extent of fragmentation reactions, and a lack of a background matrix signal interference, especially in the case of small molecule analytes ( $<500 \mathrm{Da}$ ) [8].

Therefore, there are extensive efforts to substitute traditional matrices, or to improve their properties, either by replacing organic compounds with nanoparticles of specific optical and electrochemical properties, or by an addition of nanoparticles to organic matrices. Among them, metals, and metal-oxide nanoparticles [9-12] have been applied for MALDI-TOF MS or for the mass spectrometry investigation of various molecules, including peptides, lipids, vitamins, carbohydrates, steroids/hormones, and other compounds [13-15]. Carbon-based materials such as graphene and carbon nanotubes have been tested as substrates to overcome the drawbacks of organic matrices [16]. The application of deprotonating agents such as alkyl-substituted bis-phosphazene proton sponges [17] or derivation agents to increase the ionization process of sterols has also been documented [18].

Carbon-based nanomaterials, such as graphene [19] or fluorescent carbon nanoparticles (Carbon dots, CDs) have already been used as substrates for the MALDI-TOF MS detection of low mass compounds in a negative, but also in a positive ion mode, alone or in a combination with organic matrices [20]. The high optical absorbance of CDs (>335 nm), besides their excellent physicalchemical properties such as a self-passivation, electronic conductivity, high surface area to volume ratio, good solubility in water and organic solvent [21], make them suitable matrices for detecting small molecules by the MALDI-TOF MS technique. Their electronic properties are related to condensed benzene rings, which absorb the energy and transfer it to the analyte, in a more efficient way than do conventional organic matrices [22,23]. As an efficient application of this transfer process, CDs alone or in a combination with 9-aminoacridine (9-AA) were used for the detection of mefenamic acid or nucleosides in human fluids $[20,24]$. The most probable mechanism of the CDs' positive effect is the improvement of the optical properties of 9-AA, enabling higher absorption of the laser light and energy transfer to the analyte.

Published results suggested that a high salt tolerance of CDs enables their application in real samples, such as the detection of neurotransmitters, uric acid and glucose in serum $[21,24]$ or a $\mathrm{Ru}$-complex in urine, a potential class of selective anticancer drugs [25]. In the case of a glucose analysis in serum, not only its detection but also quantification was possible with the aid of CDs, which is an advantage over other organic matrices. A graphene matrix led to a high sensitivity and resolution in the detection of non-polar compounds, such as sterols in the MALDI MS approach [26-28].
Doped CDs with N, O and P have been used as substrates for the quantification of small molecules (glucose, uric acid, or amino acids) in both modes (positive and negative), and they improved an electronic density of matrices [29-30], which is an important detection parameter.

Following the introductory works on the application of CDs as the MALDI-TOF MS matrices [25], we have synthesized raw CDs and their $N$-doped counterparts and tested their suitability for the detection of cholesterol using MALDI-TOF MS. Even though there are inexpensive colorimetric kits for the detection of cholesterol, this molecule was chosen for our study as a model system for MALDI detection of small biologically relevant compounds. Moreover, the $m / z$ position of cholesterol is in a proximity of signals arising from the MALDI matrix, making its detection challenging. Therefore, our objective is to propose a carbon-based alternative to the conventional organic substrates, 2,5-dihydroxybenzoic acid (2,5-DHB) and 2-hydroxy-5-methoxybenzoic acid (sDHB), which are commonly used to enhance the cholesterol detection. We hypothesize that that presence of functional groups, such as amine groups or carboxyl groups on the CDs surface, which affect the electron density of the carbon matrix, will advance chargetransfer reactions, and thus will make CDs a potentially suitable substrate for the detection of small molecules by MALDI-TOF MS, especially those of low polarizability such as cholesterol. It is known that being poorly polarizable, it decreases the ionization efficiency that usually leads to a low ion yield [31,32]. Cholesterol was selected as a model system because it is a low-density lipoproteins compound (LDL), whose concentration in blood should be controlled, as a high concentration may lead to the development of atherosclerosis [33-35] and also because of its presence in cellular membranes. To support our experimental findings, DFT calculations were performed to explain the mechanism of the interaction of $\mathrm{CDs} / \mathrm{N}-\mathrm{CDs}$ with cholesterol.

\section{Experimental}

\subsection{Synthesis of carbon dots nanoparticles}

Carbon dots (CDs) were prepared by a hydrothermal approach from lactose, as previously addressed in detail [36]. Briefly, lactose was treated in a Teflon lined steel reactor with $\mathrm{HCl}(1 \mathrm{M})$ at $100{ }^{\circ} \mathrm{C}$ for $3 \mathrm{~h}$ in an oven. Afterwards, the mixture was dialyzed against deionized water for $24 \mathrm{~h}$. $\mathrm{N}$-doped CDs $(\mathrm{N}$-CDs) were prepared by mixing CDs with 1,6-hexanediamine (1 g, 98\%, Sigma-Aldrich, Germany) in a Teflon lined steel reactor, and heated in an oven for $3 \mathrm{~h}$ at $100{ }^{\circ} \mathrm{C}$ (Scheme 1$)$. It was assumed that a high solubility of $1,6-$ hexanediamine in water and its nitrogen chemistry will promote the incorporation of $\mathrm{N}$-containing groups to CDs' .

\subsection{Characterization}

The morphology of CDs was evaluated by a high-resolution transmission electron microscopy (HRTEM) on a FEI Talos F200X.The AFM images were collected on Flex-AFM (Nanosurf, Switzerland) equipment, in dynamic mode (phase contrast), at a scan rate of $1 \mathrm{~Hz}$ ( $1 \mathrm{~s} /$ line; 1024 lines, 1024 points, surface area $5 \times 5$ and $\left.2.5 \times 2.5 \mu \mathrm{m}^{2}\right)$. A solution of $N$-CDs $(200 \mu \mathrm{g} / \mathrm{mL})$ in filtered ultrapure water was sonicated (15 min) and shaked every $5 \mathrm{~min}$. A drop of $20 \mu \mathrm{L}$ was placed in a freshly cleaved mica sheet and left to dry at room temperature overnight. Collected images were analyzed and profiles extracted using the free Gwyddion software v. 2.45 (Department of Nanometrology, Czech Metrology Institute, Czech Republic). A particle area and diameter distribution were obtained with a free software package Image $1.48 \mathrm{v}$. An XPS analysis was carried out on a Physical Electronics PHI 


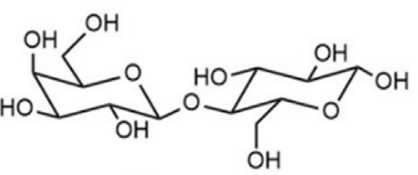

D-Lactose

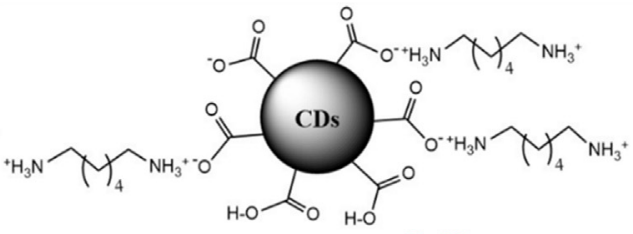

$\mathrm{N}-\mathrm{CDS}$

Scheme 1. Molecular representation of the obtained $\mathbf{N}$-CDs.

VersaProbe II spectrometer (Al- $\mathrm{K}_{\alpha}$ radiation $49.1 \mathrm{~W}, 15 \mathrm{kV}$ and $1486.6 \mathrm{eV})$. Spectra were recorded with a constant pass energy value of $29.35 \mathrm{eV}$, using a $100 \mu \mathrm{m}$ diameter circular analysis area,analyzed using PHI SmartSoft software, and processed using MultiPak 9.3 package. A Shirley-type background and GaussLorentz curves were used to determine the binding energies, which were referenced to an adventitious carbon $C 1 \mathrm{~s}$ signal (284.8 eV). Fluorescence measurements were performed in 10$\mathrm{mm}$ path-length quartz cuvettes on a fluorescence spectrometer LS55 (Perkin-Elmer, Norwalk, CT, USA) at a room temperature. A matrix-assisted laser desorption/ ionization time of flight mass spectrometry (MALDI-TOF MS) was carried out on the Autoflex Max Device (Bruker, Bremen, Germany), equipped with the SmartBeam ${ }^{\mathrm{TM}}$ laser $\left(\lambda_{\mathrm{em}}=355 \mathrm{~nm}\right)$. The maximum laser frequency was $2 \mathrm{kHz}$, and all spectra were acquired by applying $200 \mathrm{~Hz}$. A reflector detector and delayed extraction time $120 \mathrm{~ns}$ were used. The $\zeta$ potential of carbon nanoparticles were determined in phosphate buffer solution $(10 \mathrm{mM})$ using a Zetasizer Nano ZS (Malvern Instruments, U.K.) equipped with a $4 \mathrm{~mW}$ HeNe laser operating at $\lambda=633 \mathrm{~nm}$ at $25^{\circ} \mathrm{C}$, using a polycarbonate folded capillary cells, incorporated with Au plated electrodes (DTS1061). $\zeta$ were obtained automatically by the software, using the Stokes-Einstein and the Henry equation, with the Smoluchowski approximation. ${ }^{1} \mathrm{H}$ and ${ }^{13} \mathrm{C}$ NMR spectra were recorded on a Bruker Avance-III 400 plus spectrometer at room temperature operating at $400 \mathrm{MHz}\left({ }^{1} \mathrm{H}\right)$ and $100 \mathrm{MHz}\left({ }^{13} \mathrm{C}\right)$ respectively using $\mathrm{D}_{2} \mathrm{O}$ and MeOD as solvents. Chemical shifts are given in $\delta$-values (ppm) referenced to residual solvent peaks, automatically referenced by the instrument

\subsection{Preparation of samples for MALDI-TOF MS}

The matrices or substrates/nanoparticles for MALDI MS were prepared in the following way: CDs and $\mathrm{N}$-CDs were dissolved in water at a final concentration of 0.3 or $0.5 \mathrm{mg} / \mathrm{mL}$, or in a combination with 2,5-dihydroxybenzoic acid (2,5-DHB) or "super DHB" (sDHB) (both at the final concentration of $5 \mathrm{mg} / \mathrm{mL}$ ). Whereas DHB is a well known matrix [11], the so called sDHB consists of 9:1 (w/w) mixture of 2,5-DHB and 2-hydroxy-5-methoxybenzoic acid; both matrices were purchased from Sigma Aldrich (Germany). In all cases, the matrix/substrate solution was mixed with a cholesterol standard in a volume ratio 1:1. Cholesterol was used in a concentration range (maximum concentration $0.37 \mu \mathrm{M}$ ), which, as determined previously, provide a linear detector response. To test the system tolerance for inorganic salts, $\mathrm{NaCl}$ dissolved in water was added to the cholesterol solution to reach the final concentration ranging from 0 to $2 \%$. Each sample/matrix
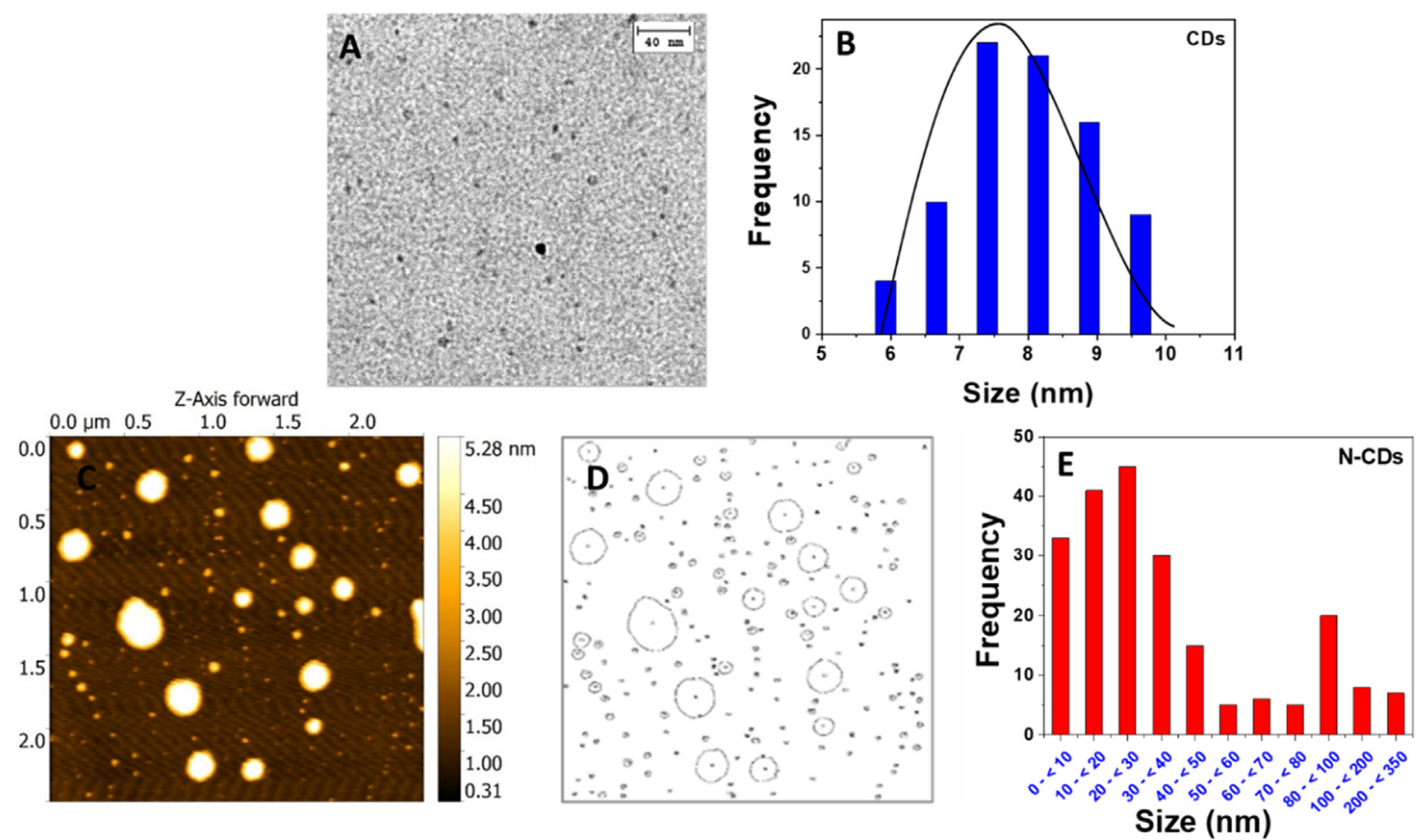

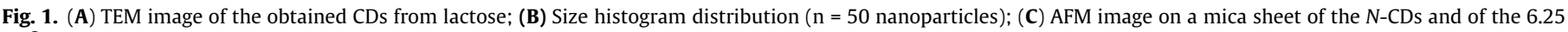
$\mu \mathrm{m}^{2}$ surface area; (D) $N$-CDs nanoparticles' counting process. E) $N$-CDs nanoparticles' size distribution. 

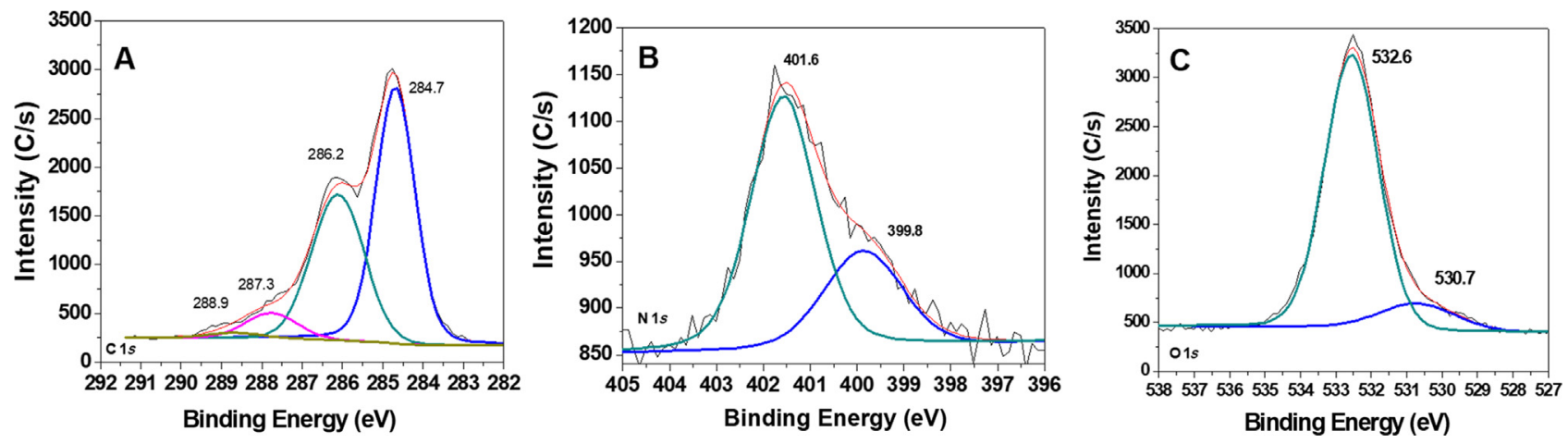

Fig. 2. XPS core level spectra of $\mathrm{N}-\mathrm{CDs}(\mathbf{A}) \mathrm{C} 1 \mathrm{~s}$, (B) N $1 s$ and (C) $01 \mathrm{~s}$.

combination was used in quadruplicate $(0.5 \mu \mathrm{L} / \mathrm{spot})$ to test the reproducibility of the method and left at the room temperature to co-crystallize. The Spectra were calibrated using the signals arising from DHB as a standard.

\subsection{Computational details}

The interactions of cholesterol with $\mathrm{CDs}$ and $\mathrm{N}$-doped carbon quantum dots $(N-C D s)$ were evaluated using a density functional theory (DFT) with a hybrid meta exchange-correlation functional M05-2X [37] corrected by the D3 version of Grimme's empirical dispersion [38], as recommended by Grimme and co-workers [39]. The def2-SVPP and def2-TZVPP basis sets have been applied to all atoms which form the systems under study $[40,41]$. The electronic structure calculations were carried out with the GAUSSIAN16 program [42]. Adsorption energies were estimated using the expressions given by Thermodynamics Statistical with programs developed by the members of our research group $[43,44]$. The potential energy surfaces, which represent the formation of complexes between cholesterol and ( $\mathrm{N}$-CDs) have been modeled using a full linear interpolation method in internal coordinates [45-50]. Molecular geometries were analyzed by MOLDEN and MacMolPlt [51,52] software.

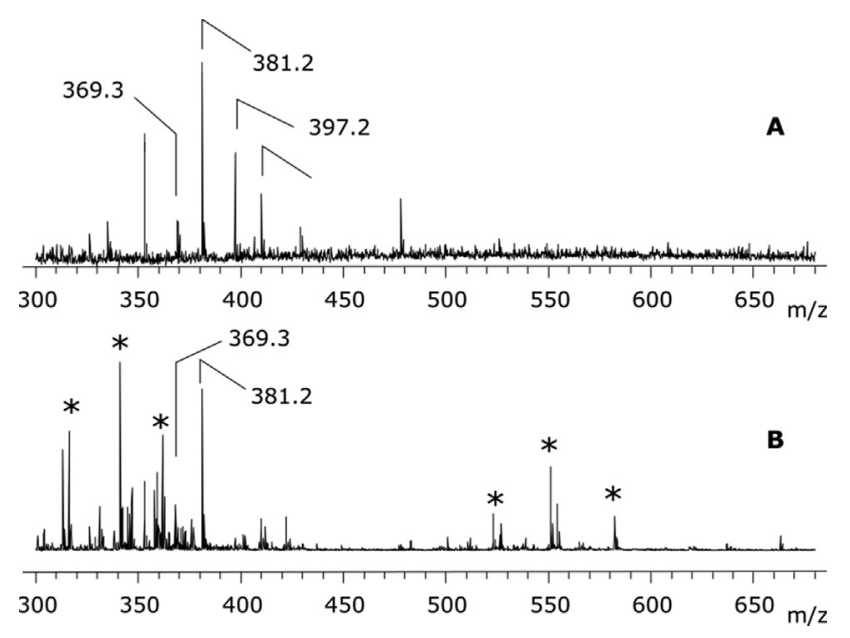

Fig. 3. Positive ion MALDI TOF mass spectra of cholesterol acquired with (A) CDs and sDHB + CDs (B). [Cholesterol] $=0.095 \mu \mathrm{M}(\mathbf{A})$ and $0.049 \mu \mathrm{M}(\mathbf{B})$. Samples were applied in the pre-mix conditions $(1: 1, \mathrm{v}: \mathrm{v})$ and the spectra were acquired with the reflector detector by averaging 2000 individual laser shots at $200 \mathrm{~Hz}$ laser frequency. Signals arising from CDs (A) and of cholesterol $(\mathbf{B})$ are indicated by $\mathrm{m} /$ $z$ ratio, whereas the spectra arising from organic matrices used are indicated by an asterisk.

\section{Results and discussion}

\subsection{Morphological analysis of CDs}

The TEM images of raw CDs obtained from lactose are shown in (Fig. 1A). Nanoparticles are well dispersed and exhibit a spherical shape with a mean size of 7-8 nm (Fig. 1B), as reported previously. The size and shape of CDs obtained in this batch, correspond to those obtained in our previous study, thus demonstrating the reproducibility of the hydrothermal synthesis process [36]. The AFM image (Fig. 1C) reveals a poly-dispersed $N$-CDs particleś size distribution. 3D topographic images obtained by AFM show the maximum particle height of $21 \mathrm{~nm}$ and $13 \mathrm{~nm}$ for the $25 \mu \mathrm{m}^{2}$ and $6.25 \mu \mathrm{m}^{2}$, respectively (Figure SI1). Profile data extracted from the $6.25 \mu \mathrm{m}^{2}$ image, is shown in Figure SI2A, where both small and big particles were selected to be analyzed. The data were leveled and normalized with the minimum value to zero. The comparison of all analyzed nanoparticles (Figure SI2B) showed their height between 1.20 and $8 \mathrm{~nm}$.

The particle area (Fig. 1D) was analyzed, and their diameter was calculated by a circle approximation. Fig. 1E shows 165 particles with a diameter between 0 and $50 \mathrm{~nm}, 39$ particles with a size range between 50 and $100 \mathrm{~nm}$, and 15 particles with sizes above $100 \mathrm{~nm}$. Overall, the AFM results reveal that $N$-CDs particles have dimensions in a nanometer range, with a spherical shape distribution. Moreover, the analysis of the shape of CDs showed a well dispersed and not aggregated spherical nanoparticles with a mean value of $7.8 \mathrm{~nm}$, which agreed with our previous results and reproducible hydrothermal synthesis approach [36].

A good homogeneity of the distribution on the MALDI plate can be achieved with small nanoparticles as a substrate and therefore the results indicate that both $\mathrm{CDs}$ and $\mathrm{N}$-CDs are good candidates to be used in the matrix. However, there is an indication that the functional groups on the $\mathrm{N}$-CDs nanoparticles surface favour the electrostatic interactions and it leads to the formation of aggregates seen in the AFM images. (Fig. 1A). This kind of interactions might also benefit the cholesterol detection.

\subsection{Surface analysis}

\subsection{1. ${ }^{1} \mathrm{H}$ NMR spectroscopy of $\mathrm{N}-\mathrm{CDs}$}

To confirm the surface functionalization of CDs with nitrogen, NMR spectra were acquired and analyzed. In the spectrum of $\mathrm{N}$ CDs in $\mathrm{D}_{2} \mathrm{O}$ (Figure SI3B), signals corresponding to three methylene residues of a diamine chain are visible. These signals are shifted in comparison with those of pure diamine (Figure SI5A). This can be explained by an ammonium salt formation from amino groups and $\mathrm{CO}_{2} \mathrm{H}$ groups on the surface of $\mathrm{CDs}$. As addressed elsewhere and based on XPS analysis [53], CDs used in this study are rich in 


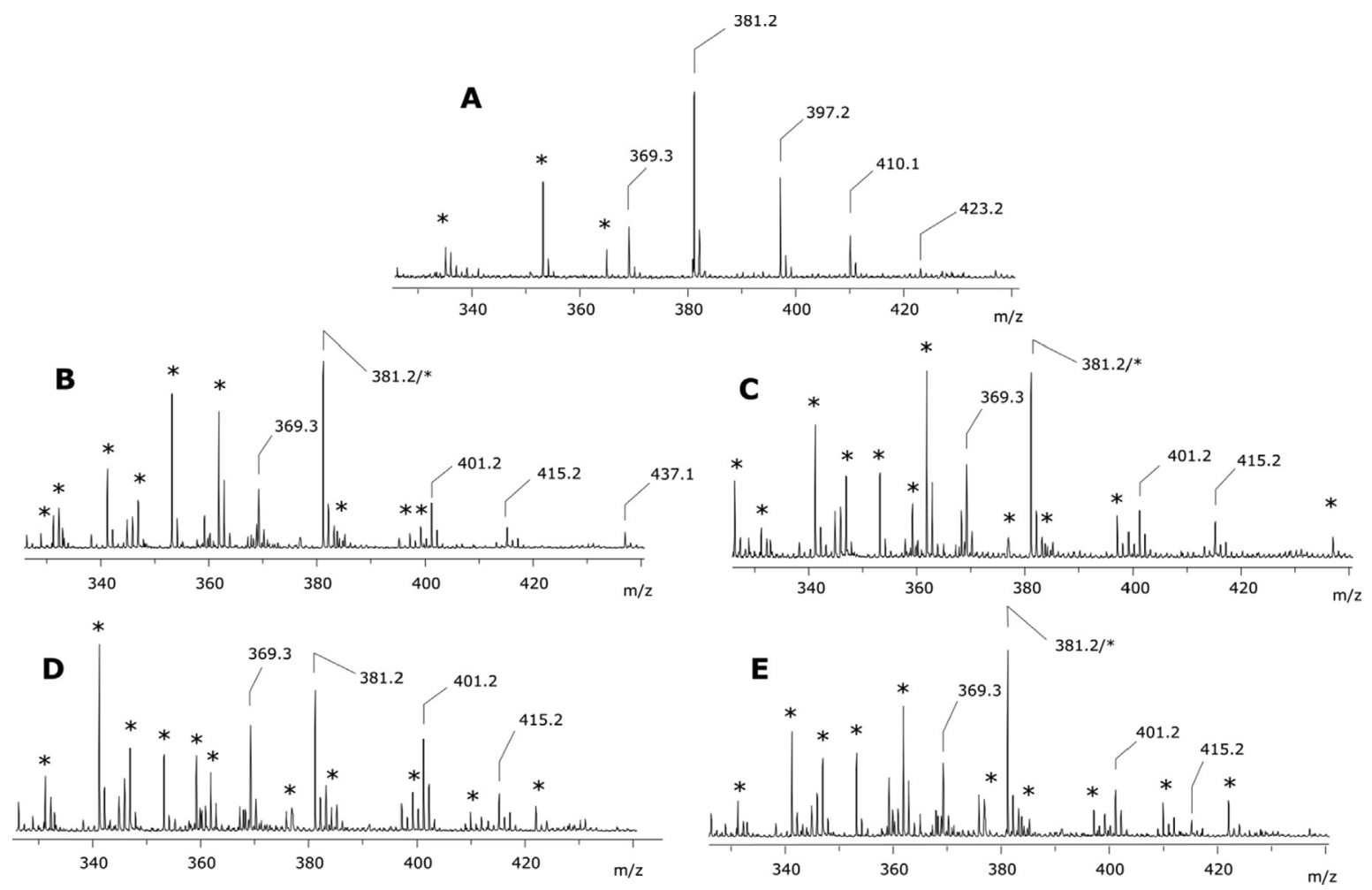

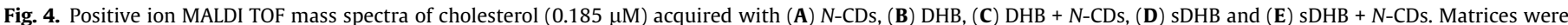

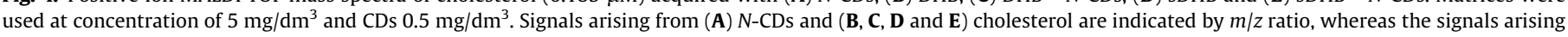
from organic matrices used are indicated by an asterisk.

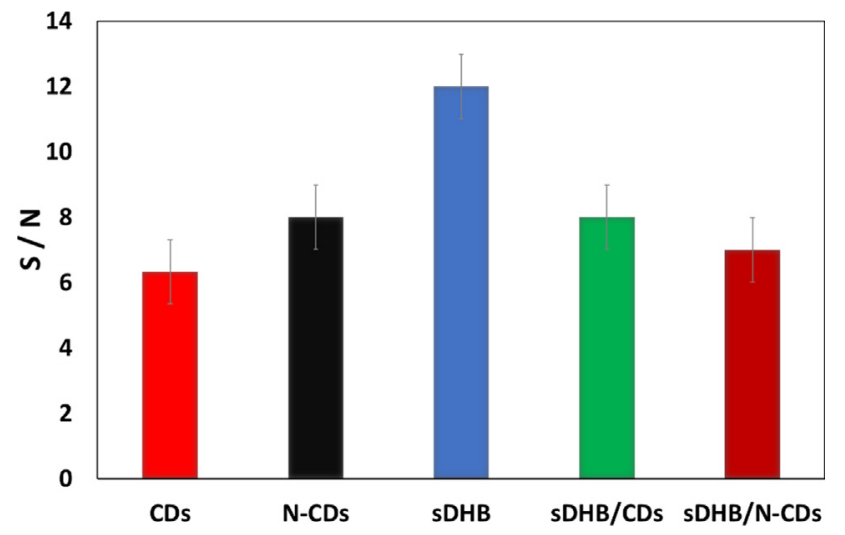

Fig. 5. The $\mathrm{S} / \mathrm{N}$ ratio of cholesterol acquired with CDs, $\mathbf{N}$-CDs, SDHB, and their combination. Bars arise from the signal at $\mathrm{m} / \mathrm{z} 369.3$ The average value from 4 measurements and standard deviation are presented. [Cholesterol] $=0.185 \mu \mathrm{M}$.

carboxylic groups. Moreover, when we added more 1,6hexanediamine to a NMR tube (Figure SI3C), methylene signals increased, but no significant peaks belonging to free amine appeared in spectra. These results support that there are free $-\mathrm{COOH}$ groups on the surface of $\mathrm{N}$-CDs, which could react with the added amino groups to give ammonium salts. The carbonyl groups of $\mathrm{O}=\mathrm{C}-\mathrm{O}^{-}$and $\mathrm{O}=\mathrm{C}-\mathrm{OH}$ were identified with ${ }^{13} \mathrm{C}$ NMR. These groups can interact with MALDI matrices and analytes such as cholesterol and inorganic cations present in mixtures. The protonated amines could act as ionic linkers between the carboxyl groups and diamine residue on the surface of $C D$ s, and this process can result in the formation of aggregates (Scheme 1) as seen in the AFM images.

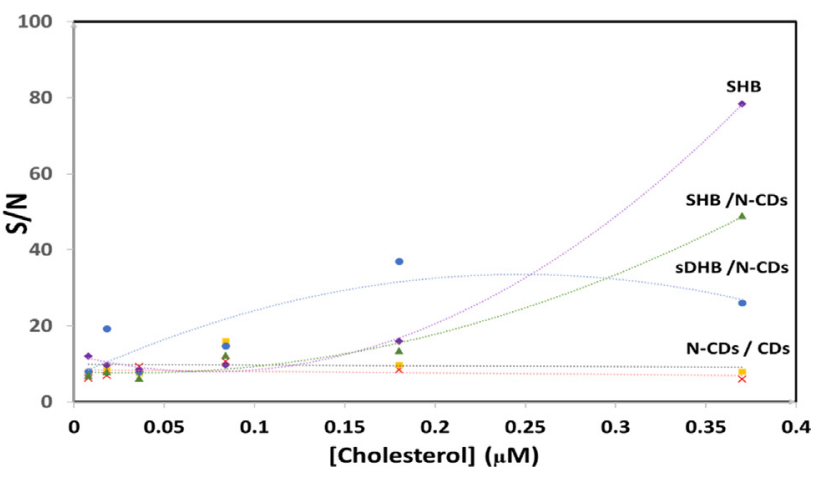

Fig. 6. Concentration dependence of the signal intensity of cholesterol acquired under various conditions and with the assistance of CDs or $N-C D s$.

To study potential interactions between CDs and cholesterol, NMR spectra of CDs@cholesterol were acquired in MeOD, after 10 min sonication. Despite the complexity of ${ }^{1} \mathrm{H}$ NMR spectra, it was possible to identify significant signals from cholesterol and diamine chains in the mixture at 2.96, 1.70 and $1.46 \mathrm{ppm}$, (diamine chain) and at $1.02(\mathrm{~s}), 0.93(\mathrm{~d}), 0.87(\mathrm{~d}, 2 \times 3 \mathrm{H})$ and $0.71(\mathrm{~s}) \mathrm{ppm}(\mathrm{c}-$ holesterol methyl), (Figure SI4). ${ }^{13} \mathrm{C}$ NMR spectra showed the zones corresponding to the signals of $\mathrm{N}$-CDs (68 to $105 \mathrm{ppm}, \mathrm{C}-\mathrm{H}$ carbons principally) and (60-63, $\mathbf{C H}_{2}$ carbons), (Figure SI5). Most of the cholesterol signals appeared from 10 to $57 \mathrm{ppm}$, and vinylic carbon $\mathbf{C}-\mathrm{H}$ - at $121 \mathrm{ppm}$. The NMR analysis showed a small shift of the signals corresponding to cholesterol acquired in the mixture with CDs or $\mathrm{N}$-CDs, compared to the signals obtained in isolated cholesterol. This indicates that the interactions between $\mathrm{N}$-CDs and cholesterol must be primarily electrostatic since the presence of a covalent or ionic bond should provoke higher shifts for the sig- 
Table 1

$\mathrm{S} / \mathrm{N}$ ratio of the signal arising from cholesterol at $\mathrm{m} / \mathrm{z} 369.3$ detected with sDHB, DHB, CDs, $\mathrm{N}-\mathrm{CDs}$, or their combination under increasing content of $\mathrm{NaCl}$.

\begin{tabular}{|c|c|c|c|c|c|}
\hline $\begin{array}{l}{[\mathrm{NaCl}] \%} \\
\text { DHB }\end{array}$ & Mean \pm SD & RSD, \% & $\begin{array}{l}{[\mathrm{NaCl}] \%} \\
\text { sDHB }\end{array}$ & Mean \pm SD & RSD, \% \\
\hline 0 & $19.7 \pm 4.1$ & 60.5 & 0 & $33.5 \pm 10.2$ & 30.5 \\
\hline 0.1 & $5.5 \pm 0$ & 1 & 0.1 & $0 \pm 0$ & 1 \\
\hline 0.2 & $8.0 \pm 0$ & 1 & 0.2 & $0 \pm 0$ & i \\
\hline 0.4 & $0.0 \pm 0$ & 1 & 0.4 & $0 \pm 0$ & I \\
\hline 0.9 & $8.0 \pm 0$ & 1 & 0.9 & $0 \pm 0$ & I \\
\hline 2.0 & $0.0 \pm 0$ & 1 & 2.0 & $0 \pm 0$ & i \\
\hline \multicolumn{3}{|l|}{$N$-CDs } & \multicolumn{3}{|l|}{ CDs } \\
\hline 0 & $15.3 \pm 4.2$ & 27.5 & 0.0 & $16.0 \pm 6.4$ & 39.9 \\
\hline 0.1 & $9.0 \pm 2.0$ & 22. & 0.1 & $19.8 \pm 5.1$ & 25.9 \\
\hline 0.2 & $15.5 \pm 3.4$ & 22.0 & 0.2 & $13.0 \pm 3.0$ & 22.7 \\
\hline 0.4 & $22.8 \pm 5.6$ & 24.4 & 0.4 & $19.8 \pm 9.1$ & 45.9 \\
\hline 0.9 & $23.8 \pm 4.6$ & 19.3 & 0.9 & $17.8 \pm 6.7$ & 37.8 \\
\hline 2.0 & $21.5 \pm 5.9$ & 27.5 & 2.0 & $17.5 \pm 4.4$ & 24.9 \\
\hline \multicolumn{3}{|c|}{ sDHB + N-CDssDHB + N-CDs } & \multicolumn{3}{|c|}{ sDHB + CDs } \\
\hline 0.1 & $0 \pm 0$ & 1 & 0.1 & $8 \pm 0$ & 1 \\
\hline 0.2 & $0 \pm 0$ & i & 0.2 & $7 \pm 0$ & i \\
\hline 0.4 & $0 \pm 0$ & I & 0.4 & $0 \pm 0$ & 1 \\
\hline 0.9 & $0 \pm 0$ & i & 0.9 & $8.7 \pm 0.6$ & 6.7 \\
\hline 2.0 & $0 \pm 0$ & i & 2.0 & $16.0 \pm 4.1$ & 25.5 \\
\hline \multicolumn{3}{|c|}{ DHB + N-CDsDHB + N-CDs } & \multicolumn{3}{|c|}{$\mathrm{DHB}+\mathrm{CDs}$} \\
\hline 0.1 & $0 \pm 0$ & 1 & 0.1 & $16.0 \pm 4.1$ & 25.5 \\
\hline 0.2 & $0 \pm 0$ & i & 0.2 & $8 \pm 0$ & 1 \\
\hline 0.4 & $0 \pm 0$ & I & 0.4 & $9 \pm 3.5$ & 38.5 \\
\hline 0.9 & $0 \pm 0$ & I & 0.9 & $11.7 \pm 2.5$ & 21.6 \\
\hline 2.0 & $0 \pm 0$ & I & 2.0 & $7.7 \pm 1.5$ & 19.9 \\
\hline
\end{tabular}

nals. Apparently, the signal of $\mathrm{CH}-\mathrm{OH}$ was shifted, and it appeared in the region of the signals arising from $\mathrm{N}$-CDs; therefore, it could not be identified in the mixture. ${ }^{13} \mathrm{C}$ NMR assignments were investigated by DEPT-135 and compared with the previously reported ones [54].

Since for the interactions of cholesterol with CDs/N-CDs, the charge of the surface is important, a zeta potential $(\zeta)$ was measured. For $N-C D s$ and CDs it was $7.8 \mathrm{mV}$ and $-6.6 \mathrm{mV}$, respectively. The positive value for $\mathrm{N}$-CDs is linked to the protonated amine groups on their surface, and negatively charged on CDs- to the $\mathrm{COOH}$ groups. These results not only confirm the presence of the hydroxyl and carboxylate functional groups on the CDs surface [36], but also clearly show the successful chemical modification of the surface of $\mathrm{N}$-CDs.

\subsubsection{XPS analysis}

The XPS results further confirms the successful surface modification of CDs with nitrogen. The CDs nanoparticles were previously analyzed by XPS [36] and the deconvolution of the C $1 \mathrm{~s}$ core energy level spectrum showed the marked contribution at $287.5 \mathrm{eV}$ assigned to carbonyl/carboxyl functionals groups. Carboxylate groups were also detected as the contribution at $289.3 \mathrm{eV}$. The surface chemical content of $\mathrm{C}$ and $\mathrm{O}$ was 89.62 and $9.71 \%$, respectively.

The surface chemical composition of $\mathrm{N}$-CDs (at. \%), after the hydrothermal process was C (66\%), O (29\%) and N (3\%), with a balance of trace atoms. The deconvoluted $\mathrm{C} 1 \mathrm{~s}, \mathrm{O} 1 \mathrm{~s}$ and $\mathrm{N} 1 \mathrm{~s}$ core energy level spectra are presented in Fig. 2A-C. The $C 1 s$ spectrum for $\mathrm{N}$-CDs was deconvoluted in four main contributions attributed to $\mathrm{C}-\mathrm{C} / \mathrm{C}-\mathrm{H}(284.7 \mathrm{eV}), \mathrm{C}-\mathrm{O} / \mathrm{C}-\mathrm{N} / \mathrm{C}-\mathrm{O}-\mathrm{C}$ (acetal) $(286.2 \mathrm{eV})$, $\mathrm{C}=\mathrm{O}(287.6 \mathrm{eV})$ and at $288.9 \mathrm{eV}$ assigned to carboxylate $(\mathrm{O}=\mathrm{C}-\mathrm{O})$ (Fig. 2A) [55]. The high-resolution N $1 s$ spectrum showed a broad asymmetric band, which was deconvoluted into contributions at 399.7 and $401 \mathrm{eV}$ assigned to amine functional groups $\left(-\mathrm{NH}_{2}\right)$ and protonated amines $\left(-\mathrm{NH}_{2}-\mathrm{H}^{+}\right)$, respectively (Fig. 2B) [56]. The deconvolution of $\mathrm{O} 1 \mathrm{~s}$ spectrum revealed two peaks: a domi-<smiles>c1ccc2cc3ccccc3cc2c1</smiles>

(A1)<smiles>O=C(O)CCc1c2ccccc2cc2ccccc12</smiles>

(B2)<smiles>NCCc1c2ccccc2cc2ccccc12</smiles>

(C3)<smiles>NC(=O)CCc1c2ccccc2cc2ccccc12</smiles>

(D4)
Scheme 2. Selected models of CDs and functionalized $N$-CDs.

nant one at $532.6 \mathrm{eV}$ which represents $\mathrm{C}-\mathrm{O} / \mathrm{C}-\mathrm{O}-\mathrm{C}$ groups at $530.7 \mathrm{eV}$ assigned to $>\mathrm{C}=\mathrm{O}$ functional groups (Fig. 2C) [56].

\subsection{MALDI-TOF MS of cholesterol with $N-C D$ s and $C D$ s with inorganic salts}

The spectra of cholesterol acquired with CDs (Fig. 3) and with DHB or SDHB, with or without $N-C D$, are presented in Fig. 4 . The number of signals arising from the matrices (indicated by an asterisk in the spectra) is much smaller when $N$-CDs are used as the substrate for MALDI-TOF MS compared to the binary system with matrices (Fig. 4). The signal at $m / z 369.3$ arises from dehydrated cholesterol, followed by the addition of a proton $\left(\mathrm{M}-\mathrm{H}_{2} \mathrm{O}+\mathrm{H}\right)$, which is the easily detectable species of cholesterol in the MS spectra. Other signals arise from oxidation products of cholesterol that can be formed upon laser illumination [57]. Under the applied conditions, no sodium adducts were detectable. Still, apart from the signal at $m / z 369.3$, other signals correspond to radical cations of oxidized products, and these are at $m / z$ 401.2, 410.2, 415.2 and 423.2, as previously described [25]. 


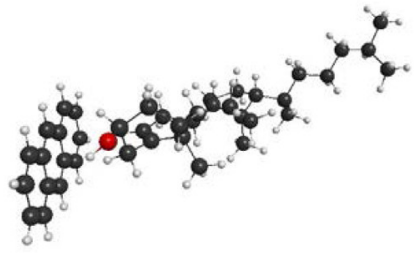

A1 (non-doped CDs)

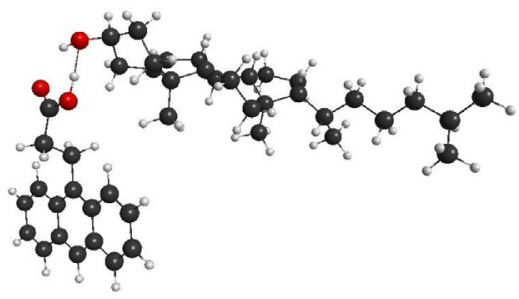

B2 ( $\left.\mathrm{HOOC}-\mathrm{CH}_{2}-\mathrm{CH}_{2} / \mathrm{N}-\mathrm{CDs}\right)$
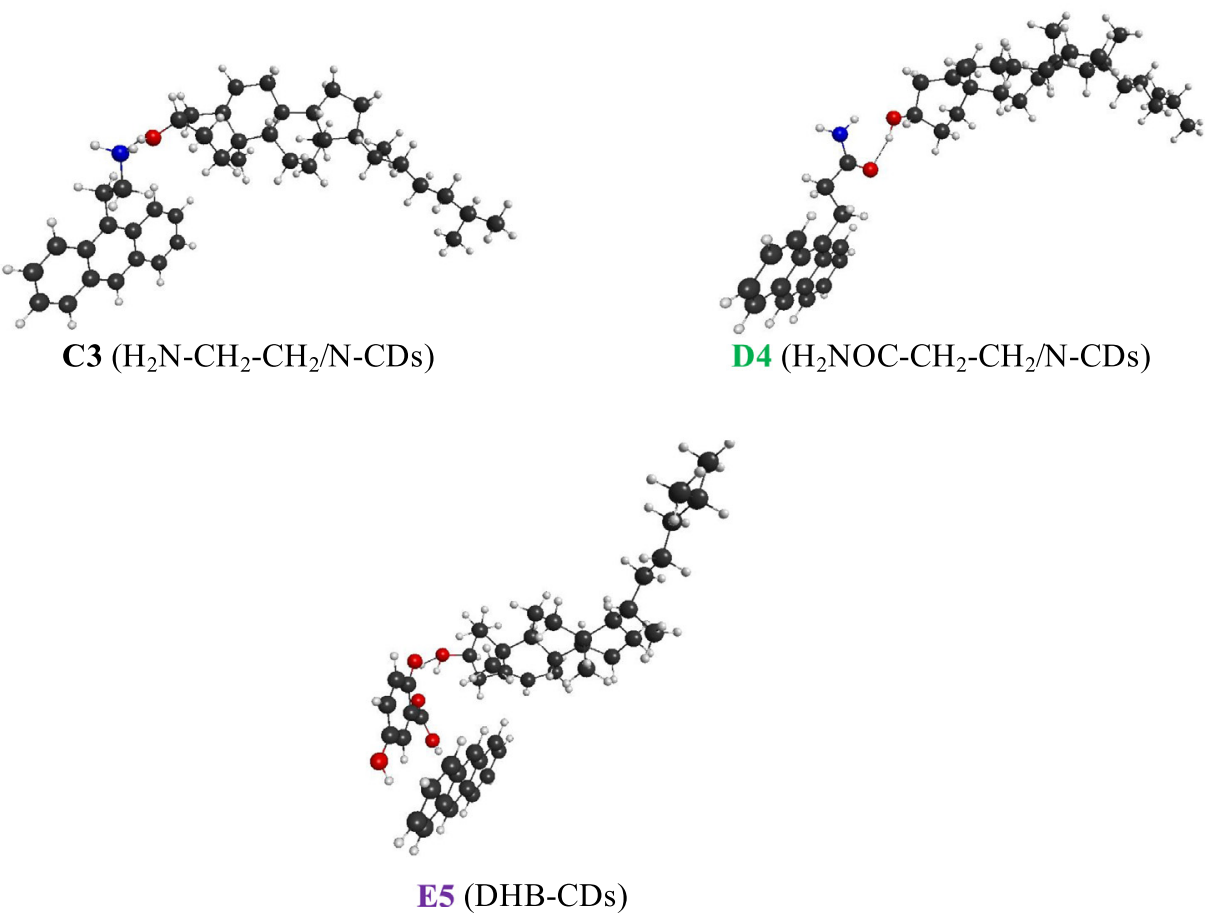

Fig. 7. M05-2X(D3)/def2-SVPP optimized geometries of the complexes formed between cholesterol CDs, DHB-CDs and $N-\mathrm{CDs}$ A1 (non-doped); $\mathbf{B 2}(-\mathrm{COOH})$; $\mathbf{C 3}\left(-\mathrm{CH} \mathrm{NH}_{2}\right)$; D4 $\left(-\mathrm{CONH}_{2}\right)$; and $\mathbf{E 5}$ (DHB-CDs).

Even though, the addition of $\mathrm{N}$-CDs to the organic matrices did not increase the detectability of cholesterol, it has slightly increased the number of signals detected in the mass region of interest. The MALDI mass spectra were acquired in a concentration range of cholesterol, with the maximum concentration of $0.37 \mu \mathrm{M}$. Because sDHB, as a matrix, yields higher $\mathrm{S} / \mathrm{N}$ for the signal at $\mathrm{m} / \mathrm{z}$ 369.3 than does DHB at all tested concentrations, this matrix was selected for further studies. It should be emphasized that $\mathrm{SDHB}$ is already a binary DHB matrix with improved properties, achieved by the addition of the low concentrations of 2,5-DHB. The addition of $\mathrm{CDs}$ or $\mathrm{N}-\mathrm{CDs}$ to the matrix did not increase the sensitivity of the detection in the system that is free from inorganic cations.

The spectra of cholesterol acquired with both CDs and $\mathrm{N}$-CDs show mostly background signals, with the $\mathrm{S} / \mathrm{N}$ ratio $>10$, which is around 8-fold lower than the highest obtained values (in terms of $\mathrm{S} / \mathrm{N}$ ratio) in the spectra. This indicates that these nanoparticles alone are not the best candidates for the MALDI MS detection of cholesterol, at least in this concentration range. On the contrary, after sDHB was used, either alone, or supplemented with nanoparticles, the cholesterol signals increased with an increase in the concentration (Fig. 5).

Compared to the spectra acquired with sDHB alone, the addition of $\mathrm{N}$-CDs induced an increase of $\mathrm{S} / \mathrm{N}$, reaching saturation at the concentration of $0.185 \mu \mathrm{M}$, whereas in the case of sDHB alone or supplemented with $\mathrm{N}$-CDs, the saturation limit was not achieved in the analyzed cholesterol concentration range (Fig. 6). However, $\mathrm{S} / \mathrm{N}$ of the detected signal at the maximum tested cholesterol concentration was lower than the intensity of the signal obtained with
sDHB. These results strongly imply the increased sensitivity of the cholesterol detection when organic matrix is supplied with CDs. In general, nanoparticles are known for their tolerance against increased inorganic salt concentrations $[10,25]$, which makes them advantageous for the MALDI TOF MS study of samples of biological origin.

In addition to proton adducts of the polymerization products, there are numerous adducts with inorganic cations, such as $\mathrm{Na}^{+}$or $\mathrm{K}^{+}$[58]. These matrix-related, or background signals in the low mass region, might lead to the saturation of a detector, thus suppressing the signals of interest, or even preventing the detection of analytes [59]. This is the case of the analysis of the low-molecular mass compounds and the reason for a lower sensitivity of the detection in the high concentration of inorganic salts in the mixture [60].

To further analyze the effects of the carbon dots addition, spectra with an increasing concentration of $\mathrm{NaCl}$ in the matrix/analyte mixture were acquired. Even though, $0.9 \%$ of $\mathrm{NaCl}$ is considered as relevant and closest to isotonic, in our approach we applied the concentrations up to $2 \%$ of $\mathrm{NaCl}$ [61], to test the limits for cholesterol detection. The spectra were acquired with SDHB, DHB, CDs and $\mathrm{N}$-CDs (alone, or in a combination with the organic matrix). Results are given in Table 1 as the mean value \pm SD. Also, RSD expressed as the percentage of the mean value is reported, to confirm the reproducibility of the method. For both organic matrices used, it was found that even the lowest concentration of $\mathrm{NaCl}$ suppressed the signal arising from cholesterol. In some cases, RSD equals 0 , which means that the detectability was not good, or the signal was detected in 1 of 4 wells. 


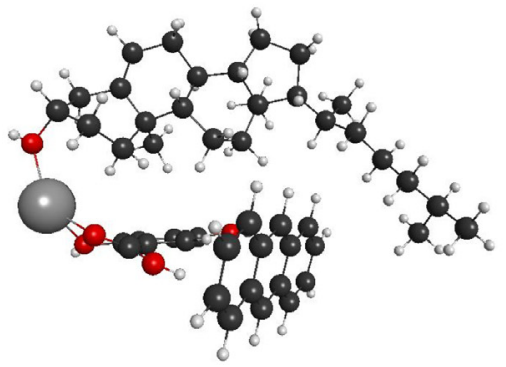

$\mathbf{E 5} \mathrm{Na}^{+}:\left(\mathrm{DHB} / \mathrm{Na}^{+} /\right.$non-doped CDs $)$

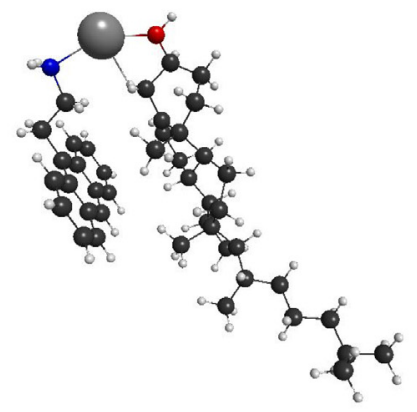

C3Na ${ }^{+}:\left(\mathrm{Na}^{+} / \mathrm{H}_{2} \mathrm{~N}-\mathrm{CH}_{2}-\mathrm{CH}_{2} / \mathrm{N}-\mathrm{CDs}\right)$

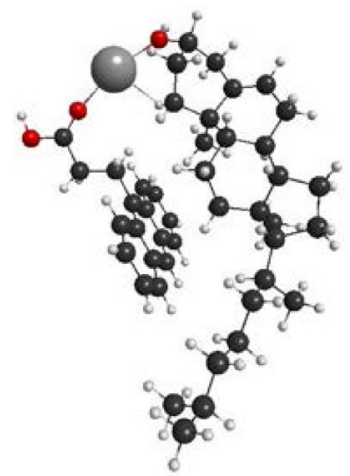

B2Na ${ }^{+}:\left(\mathrm{Na}^{+} / \mathrm{HOOC}-\mathrm{CH}_{2}-\mathrm{CH}_{2} / \mathrm{N}-\mathrm{CDs}\right)$

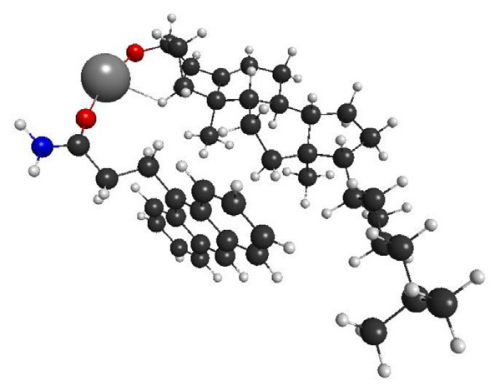

D4Na ${ }^{+}:\left(\mathrm{Na}^{+} / \mathrm{H}_{2} \mathrm{NOC}-\mathrm{CH}_{2}-\mathrm{CH}_{2} / \mathrm{N}-\mathrm{CDs}\right)$

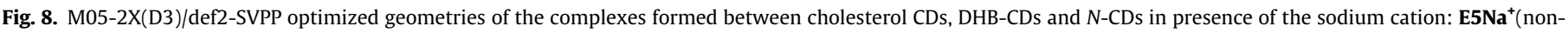
doped); $\mathbf{B 2 N a}{ }^{+}(-\mathrm{COOH}) ; \mathbf{C 3 N a}^{+}\left(-\mathrm{CH}_{2} \mathrm{NH}_{2}\right) ; \mathbf{D 4 N a}^{+}\left(-\mathrm{CONH}_{2}\right)$.

Table 2

Electronic energy of formation ( $\Delta \mathrm{E}$ in $\mathrm{kcal} / \mathrm{mol})$ of the CDs/N-CDs@ Cholesterol complexes. ${ }^{a}$

\begin{tabular}{|c|c|c|}
\hline Species $^{\mathrm{b}}$ & Formation Reaction & $\Delta E$ \\
\hline A1 & Chol + CDs $\rightarrow$ Cho $\cdots$ CDs & -10.2 \\
\hline B2 & Chol + CDs $\rightarrow$ Cho $\cdots N-C D s$ & -19.1 \\
\hline C3 & Chol + CDs $\rightarrow$ Cho $\cdots N-C D s$ & -17.9 \\
\hline D4 & Chol + CDs $\rightarrow$ Cho $\cdots$ CDs & -15.7 \\
\hline E5 & Chol + DHB-CDs $\rightarrow$ Cho DHB-CDs & -29.6 \\
\hline \multirow[t]{2}{*}{${\mathrm{B} 2 \mathrm{Na}^{+}}^{+}$} & $\mathrm{Chol}^{\cdots} \mathrm{Na}^{+}+N-\mathrm{CDs} \rightarrow \mathrm{Cho}^{\cdots} \mathrm{Na}^{+\cdots} N-\mathrm{CDs}^{\mathrm{C}}$ & -41.3 \\
\hline & Chol $+\mathrm{Na}^{+\cdots} N-\mathrm{CDs} \rightarrow \mathrm{Cho}^{\cdots} \mathrm{Na}^{+\cdots} N-\mathrm{CDs}$ & -43.7 \\
\hline \multirow[t]{2}{*}{$\mathrm{C} 3 \mathrm{Na}^{+}$} & $\mathrm{Chol}^{\cdots} \mathrm{Na}^{+}+N-\mathrm{CDs} \rightarrow \mathrm{Cho}^{\cdots} \mathrm{Na}^{+\cdots} \mathrm{N}-\mathrm{CDs}$ & -39.1 \\
\hline & Chol $+\mathrm{Na}^{+\cdots} N-\mathrm{CDs} \rightarrow$ Cho $\cdots \mathrm{Na}^{+\cdots} N-\mathrm{CDs}$ & -41.2 \\
\hline \multirow[t]{2}{*}{$\mathrm{D} \mathrm{Na}^{+}$} & $\mathrm{Chol}^{\cdots} \mathrm{Na}^{+}+\mathrm{N}-\mathrm{CDs} \rightarrow \mathrm{Cho}^{\cdots} \mathrm{Na}^{+\cdots} \mathrm{N}-\mathrm{CDs}$ & -48.0 \\
\hline & $\mathrm{Chol}+\mathrm{Na}^{+\cdots} \mathrm{N}-\mathrm{CDs} \rightarrow \mathrm{Cho}^{\cdots} \mathrm{Na}^{+\cdots} \mathrm{N}-\mathrm{CDs}$ & -42.2 \\
\hline \multirow[t]{2}{*}{$\mathrm{E} 5 \mathrm{Na}^{+}$} & $\mathrm{Chol}^{\cdots} \mathrm{Na}^{+}+\mathrm{DHB}-\mathrm{CDs} \rightarrow \mathrm{Cho}^{\cdots} \mathrm{Na}^{+} \cdots$ DHB-CDs & -60.4 \\
\hline & 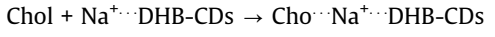 & -39.1 \\
\hline
\end{tabular}

a M05-2X(D3)/def2-SVPP.

b Geometries given in Figs. 6 and 7.

c Two possible formation reactions are considered when $\mathrm{Na}^{+}$is included.

Interestingly, the presence of $\mathrm{NaCl}$ did not suppress the cholesterol signals detectable with $\mathrm{CDs}$ and $\mathrm{N}$-CDs. On the contrary, these signals not only increased with the increasing $\mathrm{NaCl}$ concentration but achieved higher intensities in the spectra acquired with $\mathrm{N}$ CDs compared to those with CDs. In addition, RSD is somewhat lower when cholesterol spectra are acquired in the presence of $\mathrm{N}$-CDs and $\mathrm{NaCl}$. This is a clear indicator of a good reproducibility of the results. It also shows a potential for using this approach for the method optimization process to quantify cholesterol in biological samples, even without the laborious desalting, purification of the analyte and other required and time-consuming processes.

The addition of CDs to the organic matrices recovered the detectability of cholesterol in the presence of salts, whereas the addition of $\mathrm{N}$-CDs did not demonstrate the same trend (highlighted cells in Table 1). The reason for the suppression of the analyte signals in the spectra acquired with the organic matrices in the presence of $\mathrm{NaCl}$ might be in the higher number of signals arising from sDHB compared to those from DHB, which are enhanced by the presence of salts, as discussed above. In addition to this, we cannot exclude the possibility of the chemical interactions between carboxyl groups of the benzene ring of sDHB and DHB and amines of $\mathrm{N}$-CDs, which might affect the cholesterol detectability under these conditions. In any case, this approach is promising, since the detectable concentration of cholesterol was in the micromolar range $(\mu \mathrm{mol} / \mathrm{L})$, whereas the physiologically relevant concentrations are 1000 times higher [60].

\subsection{Interaction of $\mathrm{N}-\mathrm{CD}$ s with cholesterol}

\subsubsection{Chemical model}

Theoretical studies were performed with the aim to explain the results obtained with MALDI TOF MS of cholesterol using the organic matrices, CDs, and the binary systems (organic matrix/ CDs. Taking into consideration that CDs consist of a carbon core 


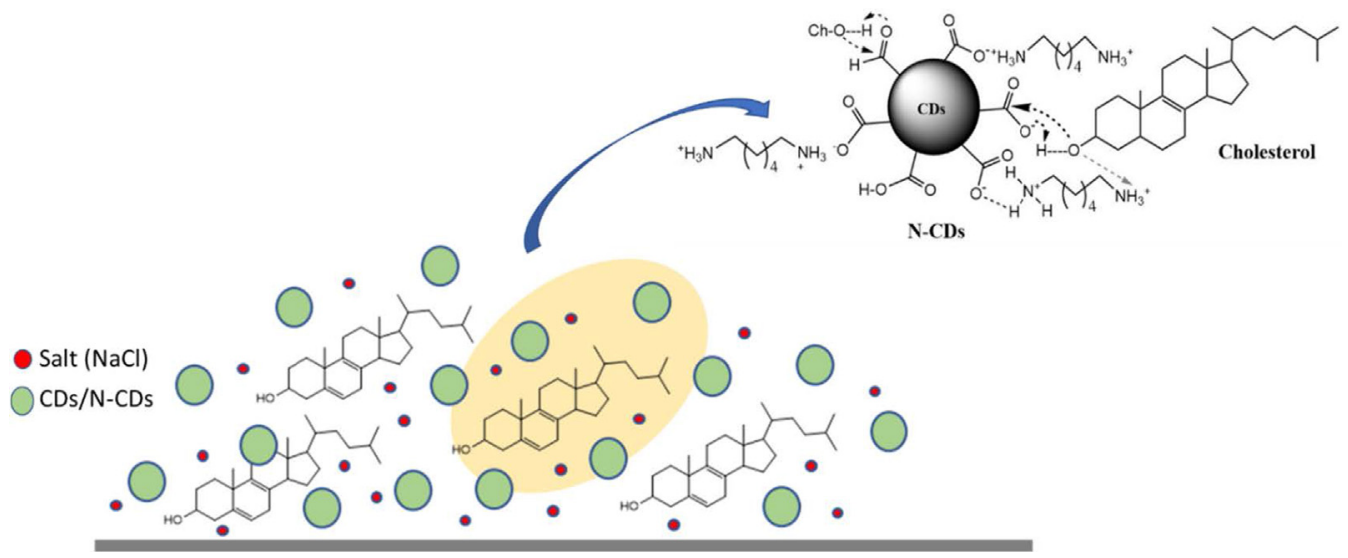

Scheme 3. Molecular representation of the interaction between cholesterol and CDs / N-CDs nanoparticles.

of a nanometer size, which is surrounded by amorphous carbon frames decorated with different chemical substituents, e.g., amide $\left(\mathrm{O}=\mathrm{C}-\mathrm{NH}_{2}\right)$, amine $\left(-\mathrm{CH}_{2} \mathrm{NH}_{2}\right)$ or carboxylic $(\mathrm{O}=\mathrm{C}-\mathrm{OH})$ groups, the CDs and $\mathrm{N}$-CDs models selected to study the cholesterol interactions with such functionalized carbon nanoparticles consist of various chemical moieties bound at one of the carbon atoms of a central ring of anthracene, as shown in Scheme 2. The model corresponding to the non-doped CDs is also shown in this Scheme. These structures agree with the models applied for the studies of analogous types of materials such as other CDs or $N$-doped 3Dgraphene quantum dots [25,62-64].

\subsubsection{Interaction of cholesterol with $N-C D s$}

Following the structural models proposed in Scheme 2, the types of interactions between cholesterol and CDs or $N$-CDs or the binary systems (organic matrix/CDs were investigated with a focus on the identification of the factors affecting the detectability of cholesterol by MALDI-TOF MS. Fig. 7 shows the geometries of target complexes with a minimum energy. The effect of $\mathrm{Na}^{+}$presence in the system was also investigated (optimized geometries are given in Fig. 7). Three types of interactions were considered: Type I as the bonding of cholesterol and pristine CDs throughout dispersive forces

(Fig. 6, A1); Type II as hydrogen bonds, which leads to the formation of cholesterol-CDs/ $N$-CDs complexes (Fig. 6, [B2, C3, D4]; Type III (Fig. 7) as a sodium bridge wehre sodium links cholesterol and $\mathrm{N}$-CDs (Fig. 7, B2Na ${ }^{+}, \mathbf{C}^{+} \mathrm{Na}^{+}$and $\mathbf{D} 4 \mathrm{Na}^{+}$) or cholesterol and binary systems (Fig. 8, E5Na ${ }^{+}$). These three types of interactions are noncovalent and purely coulombic [65] and they are presented in Scheme 2, The energies of complexes formation representing the stability of the complexes (Figs. 7 and 8) are presented in Table 2.

The calculations showed that the inclusion of the sodium cation or DHB into the geometries of the complexes increases the stabilization energy, which agrees with the experimental results showing that in the presence of $\mathrm{NaCl}$ the cholesterol signals are suppressed in the binary system. Thus, the more stable complexes are generated, the lower yield of cholesterol-related ions is generated and thus its detection is inhibited. On the other hand, with only CDs and $\mathrm{Na}^{+}$in the system, the complexes formed are less stable, and thus the cholesterol is more easily dehydrated and ionized (detectable in the spectra). Without $\mathrm{NaCl}$ cholesterol readily reacts with $\mathrm{CDs}$ that contains more of the $-\mathrm{COOH}$ groups on the surface and it contributes to the dehydration of cholesterol and thus to the higher ion yield.

The calculated ionization potentials, vertical excitations, emission energies and dipole moments of the species represented in Figs. 7 and 8 are summarized Table SI 1 of the Supplementary Infor- mation. The potential energy surfaces that led to the formation of the molecular complexes between cholesterol and $N$-CDs are represented in Figure SI7. They were obtained using a full linear interpolation method in internal coordinates. The results clearly show the smaller ionization potentials of the complexes formed with CDs and cholesterol in the presence of $\mathrm{Na}^{+}$, compared to those of the binary systems (with DHB).

While the B2 and C3 complexes are barrierless (Figure SI6) the D4 complex needs to overcome a small barrier and this barrier is CDs acting as attractors. The estimated reaction enthalpies $\left(\Delta_{\mathrm{r}} \mathrm{H}\right)$ and Gibbs free energies $\left(\Delta_{\mathrm{r}} \mathrm{G}\right)$ of such complexes at $298.15 \mathrm{~K}$ indicate that the only stable complex with the negative Gibbs free energy is A1, that involves - $\mathrm{COOH}$ group on the CDs particle surface (Table SI2). This confirms a good suitability of CDs for the detection of cholesterol in the presence of $\mathrm{Na}^{+}$and in a binary system with matrices.

Based on the experimental and theoretical data, it is proposed (Scheme 3) that the interactions of cholesterol with the $-\mathrm{COOH}$ groups of CDs on the MALDI target lead, upon laser illumination, to the electron transfer reactions and promote dehydration, desorption, and ionization of cholesterol. The results suggest that the clusters generated on the sample plate contains more than one molecule of cholesterol interacting with the single CDs nanoparticle, thus increasing the yield of cholesterol-derived ions. The absence of $\mathrm{Na}^{+}$- adducts with cholesterol in the spectra indicates that this inorganic ion is mostly bounded to CDs. In the case of $\mathrm{N}$-CDs, the amount of cholesterol bound to $-\mathrm{COOH}$ is smaller, due to the smaller amount of these groups on the surface of $\mathrm{N}$ $\mathrm{CDs}$, thus resulting in the somewhat lower signal intensity, compared to that in the presence of CDs.

\section{Conclusions}

The results presented support our hypothesis that presence of functional groups, such as amine groups or carboxyl groups on the CDs surface, which affect the electron density of the carbon matrix, will advance charge-transfer reactions, and thus will make CDs a potentially suitable substrate for the detection of small molecules by MALDI-TOF MS. Specifically, we have shown that the high content of the $\mathrm{COOH}$ groups on the surface of CDs helps to recover cholesterol signals in MALDI TOF mass spectra when acquired with DHB in the presence of inorganic salts. On the other hand, the addition of $\mathrm{N}$-CDs with a small amount of $\mathrm{COOH}$, did not advance the cholesterol signals acquired with the organic matrices. Nevertheless, without the organic matrix and only with the assistance of $\mathrm{N}$-CDs cholesterol signals were not suppressed in the presence of $\mathrm{NaCl}$. Additionally, $\mathrm{N}$-CDs led to the higher homogeneity of 
the analyte/substrate distribution on the sample plate than did CDs, which is reflected in the low RSD values. This is explained by both the positive and negative charge on the $\mathrm{N}$-CDs surface. Thus, because of its specific chemistry, $N$-CDs has a potential to quantify cholesterol in samples of biological origin by the MALDI TOF mass spectrometry. Theoretical data supported the experimental results obtained with $\mathrm{CDs} / \mathrm{N}$-CDs, in terms of the sensitivity of cholesterol detection in our specific binary system. The low Gibbs energy of the complex formation and, subsequently the high complex stability, led to an advanced detectability of cholesterol by MALDI TOF MS. In addition, the small dipole moment and low excitation energy of the complex between cholesterol and CDs resulted in an increased cholesterol detectability upon addition of $\mathrm{Na}^{+}$, which is important for the cholesterol/ and other small molecules detection in physiological solutions. The results of this study can open a new research path of functionalization of carbons dots to advance MALDI TOF MS of various molecules.

\section{Declaration of Competing Interest}

The authors declare that they have no known competing financial interests or personal relationships that could have appeared to influence the work reported in this paper.

\section{Acknowledgements}

M. Algarra thanks to the Spanish Ministerio de Economía, Industria y Competividad (RTI2018-099668-BC22). D. Huodova, R. Castro, M. Petković J. Rodrigues thanks to FCT through the CQM Base Fund - UIDB/00674/2020, and Programmatic FundUIDP/00674/2020, and by ARDITI, through the project M1420-010145-FEDER-000005 - $\mathrm{CQM}^{+}$(Madeira 14-20 Program) M142009-5369-FSE-000002 post doc grant. M. Petković acknowledges the support of the Ministry of Education, Science and Technological Development of the Republic of Serbia (Contract No. 451-0368/2020-14/200017). The authors also acknowledged the Programa de Cooperación Territorial INTERREG V-A MAC 2014-2020 through the Project Inv2Mac (MAC2/4.6d/229). Juan Soto thanks R. Larrosa and D. Guerrero for the technical support in running the calculations and the SCBI (Supercomputer and Bioinformatics) of the Univ. Málaga for computer and software resources.

\section{Appendix A. Supplementary material}

Supplementary data to this article can be found online at https://doi.org/10.1016/j.jcis.2021.02.004.

\section{References}

[1] A.E. Clark, E.J. Kaleta, A. Arora, D.M. Wolk, Matrix-Assisted Laser Desorption Ionization-Time of Flight Mass Spectrometry: A fundamental shift in the routine practice of clinical microbiology, Clin. Microbiol. Rev. 26 (2013) 547603, https://doi.org/10.1128/CMR.00072-12.

[2] R. Kaufmann, Matrix-assisted laser desorption ionization (MALDI) mass spectrometry: a novel analytical tool in molecular biology and biotechnology, J. Biotech. 41 (1995) 155-175, https://doi.org/10.1016/01681656(95)00009-f.

[3] G. Croxatto, G. Prod'hom, G. Greub, Gilbert, Applications of MALDI-TOF mass spectrometry in clinical diagnostic microbiology, FEMS Microbiol. Rev. 36 (2012) 380-407, https://doi.org/10.1111/j.1574-6976.2011.00298.x.

[4] J. Leopold, Y. Popkova, K.M. Engel, J. Schiller, Recent Developments of Useful MALDI Matrices for the Mass Spectrometric Characterization of Lipids, Biomolecules 8 (2018) 173, https://doi.org/10.3390/biom8040173.

[5] M. Petković, J. Leopold, I. Popović, D. Dimić, J. Ilić, M. Nenadović, Z. Rakočević, J. Schiller, Performances of ionic liquid matrices with butyl ammonium counterion for matrix-assisted laser desorption/ionization mass spectrometric detection and analysis of sucralfate, J. Carbohydr. Chem. 39 (2020) 1-23, https://doi.org/10.1080/07328303.2019.1669633.
[6] A. Maus, R. Mignon, F. Basile, Enhanced protein identification using graphitemodified MALDI plates for offline LC-MALDI-MS/MS bottom-up proteomics, Anal. Biochem. 545 (2018) 31-37, https://doi.org/10.1016/j.ab.2018.01.002.

[7] S.S. Basu, M.H. McMinn, B. Giménez-Cassina Lopéz, M.S. Regan, E.C. Randall, A. R. Clark, C.R. Cox, N.Y.R. Agar, Metal Oxide Laser Ionization Mass Spectrometry Imaging (MOLI MSI) Using Cerium (IV) Oxide, Anal. Chem. 91 (2019) 68006807, https://doi.org/10.1021/acs.analchem.9b00894.

[8] C.D. Calvano, A. Monopoli, T.R.I. Cataldi, F. Palmisano, MALDI matrices for low molecular weight compounds: an endless story?, Anal Bioanal. Chem. 410 (2018) 4015-4038, https://doi.org/10.1007/s00216-018-1014-X.

[9] M. Lu, X. Yang, Y. Yang, P. Qin, X. Wu, Z. Cai, Nanomaterials as Assisted Matrix of Laser Desorption/Ionization Time-of-Flight Mass Spectrometry for the Analysis of Small Molecules, Nanomaterials 7 (2017) 87, https://doi.org/ 10.3390/nano7040087.

[10] M. Radisavljević, T. Kamčeva, I. Vukićević, M. Radoičić, Z. Šaponjić, M. Petković, Colloidal $\mathrm{TiO}_{2}$ nanoparticles as substrates for M(S)ALDI mass spectrometry of transition metal complexes: Colloidal $\mathrm{TiO}_{2}$ nanoparticles as substrates for $\mathrm{M}(\mathrm{S})$ ALDI MS, Rapid Commun. Mass Spectrom. 26 (2012) 2041-2050, https://doi. org/10.1002/rcm.6320.

[11] I.A. Popović, M. Nešić, M. Vranješ, Z. Šaponjić, M. Petković, SALDI-TOF-MS analyses of small molecules (citric acid, dexasone, vitamins $\mathrm{E}$ and $\mathrm{A}$ ) using $\mathrm{TiO}_{2}$ nanocrystals as substrates, Anal. Bioanal. Chem. 408 (2016) 7481-7490, https://doi.org/10.1007/s00216-016-9846-8.

[12] L. Xu, M. Kliman, J.G. Forsythe, Z. Korade, A.B. Hmelo, N.A. Porter, J.A. McLean, Profiling and Imaging Ion Mobility-Mass Spectrometry Analysis of Cholesterol and 7-Dehydrocholesterol in Cells Via Sputtered Silver MALDI, J. Am. Soc. Mass Spectrom. 26 (2015) 924-933, https://doi.org/10.1007/s13361-015-1131-0.

[13] Q. Shen, W. Dong, M. Yang, J.T. Baibado, Y. Wang, I. Alqouqa, H.-Y. Cheung, Lipidomic study of olive fruit and oil using TiO2 nanoparticle-based matrix solid-phase dispersion and MALDI-TOF/MS, Food Res. Int. 54 (2013) 20542061, https://doi.org/10.1016/j.foodres.2013.10.001.

[14] G. Gedda, H.-F. Wu, Fabrication of surface modified ZnO nanorod array for MALDI-MS analysis of bacteria in a nanoliter droplet: a multiple function biochip, Sensor and Actuat B-Chem. 288 (2019) 667-677, https://doi.org/ 10.1016/j.snb.2019.02.011.

[15] E. Beasley, S. Francese, T. Bassindale, Detection and Mapping of Cannabinoids in Single Hair Samples through Rapid Derivatization and Matrix-Assisted Laser Desorption Ionization Mass Spectrometry, Anal. Chem. 88 (2016) 1032810334.

[16] C. Shi, J. Menga, C. Deng, Facile synthesis of magnetic graphene and carbon nanotube composites as a novel matrix and adsorbent for enrichment and detection of small molecules by MALDI-TOF MS, J. Mater. Chem. 22 (2012) 20778-20785, https://doi.org/10.1039/C2JM34745H.

[17] C.D. Calvano, T.R.I. Cataldi, J.F. Kögel, A. Monopoli, F. Palmisano, J. Sundermeyer, Superbasic alkyl-substituted bisphosphazene proton sponges: a new class of deprotonating matrices for negative ion matrix-assisted ionization/laser desorption mass spectrometry of low molecular weight hardly ionizable analytes, Rapid Commun. Mass Spectrom. 30 (2016) 16801686, https://doi.org/10.1002/rcm.7604.

[18] I. Hailat, R.J. Helleur, Direct analysis of sterols by derivatization matrixassisted laser desorption/ionization time-of-flight mass spectrometry and tandem mass spectrometry, Rapid Commun. Mass Spectrom. 28 (2014) 149158, https://doi.org/10.1002/rcm.6766.

[19] Q. Min, X. Zhang, X. Chen, S. Li, J.J. Zhu, N-Doped Graphene: An Alternative Carbon-Based Matrix for Highly Efficient Detection of Small Molecules by Negative Ion MALDI-TOF MS, Anal. Chem. 86 (2014) 9122-9130, https://doi. org/10.1021/ac501943n.

[20] C. Yongli, G. Dan, B. Hangrui, L. Hongxia, L. Shuo, J. Yuyang, Carbon Dots and 9AA as a Binary Matrix for the Detection of Small Molecules by MatrixAssisted Laser Desorption/Ionization Mass Spectrometry, J. Am. Soc. Mass Spectrom. 27 (2016) 1227-1235, https://doi.org/10.1007/s13361-016-1396-y.

[21] S.Y. Lim, W. Shen, Z. Gao, Carbon quantum dots and their applications, Chem. Soc. Rev. 44 (2015) 362-381, https://doi.org/10.1039/C4CS00269E.

[22] W. Xiao, F. Yongqiang, D. Peipei, H. Jianfeng, A Mini Review on Carbon Quantum Dots: Preparation, Properties, and Electrocatalytic Application, Front. Chem. 7 (2019) 671, https://doi.org/10.3389/fchem.2019.00671.

[23] S. Sagbas, N. Sahiner, Carbon dots: preparation, properties, and application. Cap 22, (Ed A. Khan, M. Jawaid, Inamuddin, A. M. Asiri), Nanocarbon and its Composites, Preparation, Properties and Applications. In Woodhead Publishing Series in Composites Science and Engineering (2019) 651-676. https://doi.org/ 10.1016/B978-0-08-102509-3.00022-5

[24] G. Gedda, S. Pandey, M.L. Bhaisare, H.F. Wu, Facile synthesis of gold/gadolinium-doped carbon quantum dot nanocomposites for magnetic resonance imaging and photothermal ablation therapy, RSC Adv. 4 (2014) 38027-38033, https://doi.org/10.1039/C7TB01139C.

[25] N. Nunes, I. Popović, E. Abreu, D. Maciel, J. Rodrigues, J. Soto, M. Algarra, M. Petković, Detection of Ru potential metallodrug in human urine by MALDI-TOF mass spectrometry: validation and options to enhance the sensitivity, Talanta 222 (2021), https://doi.org/10.1016/j.talanta.2020.121551 121551.

[26] K.M. Shahnawaz, M.L. Bhaisare, S. Pandey, A. Talib, S.M. Wu, S.K. Kailasa, H.F. $\mathrm{Wu}$, Exploring the ability of water-soluble carbon dots as matrix for detecting neurological disorders using MALDI-TOF MS, Int. J. Mass Spectrom. 393 (2015) 25-33, https://doi.org/10.1016/j.ijms.2015.10.007.

[27] S. Chen, H. Zheng, J. Wang, J. Hou, Q. He, H. Liu, C. Xiong, X. Kong, Z. Nie, Carbon Nanodots As a Matrix for the Analysis of Low-Molecular-Weight Molecules in Both Positive- and Negative-Ion Matrix-Assisted Laser Desorption/Ionization 
Time-of-Flight Mass Spectrometry and Quantification of Glucose and Uric Acid in Real Samples, Anal. Chem. 85 (2013) 6646-6652, https://doi.org/10.1021/ ac401601r.

[28] X. Dong, J. Cheng, J. Li, Y. Wang, Graphene as a Novel Matrix for the Analysis of Small Molecules by MALDI-TOF MS, Anal. Chem. 82 (2010) 6208-6214, https://doi.org/10.1021/ac101022m.

[29] D. Wang, Y. Gao, Y. Chen, G. Hu, H. Liu, Y. Jiang, Development of N,S-doped carbon dots as a novel matrix for the analysis of small molecules by negative ion MALDI-TOF MS, RSC Adv. 6 (2016) 79043-79049, https://doi.org/10.1039/ C6RA12131D.

[30] H. Zhao, Y. Li, J. Wang, M. Cheng, Z. Zhao, H. Zhang, C. Wang, J. Wang, Y. Qiao, J. Wang, Dual-Ion-Mode MALDI MS Detection of Small Molecules with the O-P, N-Doped Carbon/Graphene Matrix, ACS Appl. Mater. Interf. 10 (2018) 3773237742, https://doi.org/10.1021/acsami.8b14643.

[31] W. Lu, Y. Li, R. Li, S. Shuang, C. Dong, Z. Cai, Facile Synthesis of N-Doped Carbon Dots as a New Matrix for Detection of Hydroxy-Polycyclic Aromatic Hydrocarbons by Negative-Ion Matrix-Assisted Laser Desorption/Ionization Time-of-Flight Mass Spectrometry, ACS Appl. Mater. Interf. 8 (2016) 1297612984, https://doi.org/10.1021/acsami.6b01510.

[32] Z. Lin, J. Wu, Y. Dong, P. Xie, Y. Zhang, Z. Cai, Nitrogen and Sulfur Co-doped Carbon-Dot-Assisted Laser Desorption/Ionization Time-of-Flight Mass Spectrometry Imaging for Profiling Bisphenol S Distribution in Mouse Tissues, Anal. Chem. 90 (2018) 10872-10880, https://doi.org/10.1021/acs. analchem.8b02362.

[33] W.J. Griffiths, Tandem mass spectrometry in the study of fatty acids, bile acids, and steroids, Mass Spectrom. Rev. 22 (2003) 81-152, https://doi.org/ $10.1002 /$ mas. 10046.

[34] K. Jansen, A.F. van der Steen, M. Wu, H.M. van Beusekom, G. Springeling, X. Li, Q. Zhou, K. Kirk Shung, D.P. de Kleijn, G. van Soest, Spectroscopic intravascular photoacoustic imaging of lipids in atherosclerosis, J. Biomed. Opt. 19 (2014), https://doi.org/10.1117/1.JBO.19.2.026006 026006.

[35] D.J. McNamara, Dietary cholesterol, and atherosclerosis, Biochim. et Biophys. Acta 1529 (2000) 310-320, https://doi.org/10.1016/s1388-1981(00)00156-6.

[36] B.B. Campos, C. Abellán, M. Zougagh, J. Jimenez-Jimenez, E. RodríguezCastellón, J.C.G. Esteves da Silva, A. Ríos, M. Algarra, Fluorescent chemosensor for pyridine based on N-doped carbon dots, J. Coll. Interf. Sci. 458 (2015) 209-216, https://doi.org/10.1016/j.jcis.2015.07.053.

[37] Y. Zhao, N.E. Schultz, D.G. Truhlar, Design of Density Functionals by Combining the Method of Constraint Satisfaction with Parametrization for Thermochemistry, Thermochemical Kinetics, and Noncovalent Interactions, J. Chem. Theory Comput. 2 (2006) 364-382, https://doi.org/10.1021/ ct0502763.

[38] S. Grimme, J. Antony, S. Ehrlich, H. Krieg, A consistent and accurate ab initio parametrization of density functional dispersion correction (DFT-D) for the 94 elements H-Pu, J. Chem. Phys. 132 (2010), https://doi.org/10.1063/1.3382344 154104.

[39] L. Goerigk, A. Hansen, C. Bauer, S. Ehrlich, A. Najibi, S. Grimme, A look at the density functional theory zoo with the advanced GMTKN55 database for general main group thermochemistry, kinetics and noncovalent interactions, Phys. Chem. Chem. Phys. 19 (2017) 32184-32215, https://doi.org/10.1039/ c7cp04913g.

[40] F. Weigend, R. Ahlrichs, Balanced basis sets of split valences, triple zeta valence and quadruple zeta valence quality for $\mathrm{H}$ to $\mathrm{Rn}$ : Design and assessment of accuracy, Phys. Chem. Chem. Phys. 7 (2005) 3297, https://doi.org/10.1039/ b508541a.

[41] F. Weigend, Accurate Coulomb-fitting basis sets for $\mathrm{H}$ to Rn, Phys. Chem. Chem. Phys. 8 (2006) 1057, https://doi.org/10.1039/b515623h.

[42] Gaussian 16, Revision A.03, M. J. Frisch et al. Gaussian, Inc., Wallingford CT, 2016 (accessed April 22, 2020).

[43] J. Soto, E. Imbarack, I. López-Tocón, S. Sánchez-Cortés, J.C. Otero, P. Leyton, Application of surface-enhanced resonance Raman scattering (SERS) to the study of organic functional materials: electronic structure and charge transfer properties of 9,10-bis((E)-2-(pyridin-4-yl)vinyl)anthracene, RSC Adv. 9 (2019) 14511-14519, https://doi.org/10.1039/C9RA01269A.

[44] I. López-Tocón, S. Valdivia, J. Soto, J.C. Otero, F. Muniz-Miranda, M.C. Menziani, M. Muniz-Miranda, A DFT Approach to the Surface-Enhanced Raman Scattering of 4-Cyanopyridine Adsorbed on Silver Nanoparticles, Nanomaterials. 9 (2019) 1211, https://doi.org/10.3390/nano9091211.

[45] J. Soto, J.C. Otero, F.J. Avila, D. Peláez, Conical intersections and intersystem crossings explain product formation in photochemical reactions of aryl azides, Phys. Chem. Chem. Phys. 21 (2019) 2389-2396, https://doi.org/10.1039/ C8CP06974C.

[46] J. Soto, J.C. Otero, Conservation of El-Sayed's Rules in the Photolysis of Phenyl Azide: Two Independent Decomposition Doorways for Alternate Direct
Formation of Triplet and Singlet Phenylnitrene, J. Phys. Chem. A 123 (2019) 9053-9060, https://doi.org/10.1021/acs.jpca.9b06915.

[47] D. Aranda, F.J. Avila, I. López-Tocón, J.F. Arenas, J.C. Otero, J. Soto, An MSCASPT2 study of the photodecomposition of 4-methoxyphenyl azide: role of internal conversion and intersystem crossing, Phys. Chem. Chem. Phys. 20 (2018) 7764-7771, https://doi.org/10.1039/C8CP00147B.

[48] D. Peláez, J.F. Arenas, J.C. Otero, J. Soto, A complete active space self-consistent field study of the photochemistry of nitrosamine, J. Chem. Phys. 125 (2006), https://doi.org/10.1063/1.2360259 164311.

[49] J. Soto, D. Peláez, J.C. Otero, F.J. Ávila, J.F. Arenas, Photodissociation mechanism of methyl nitrate. A study with the multistate second-order multiconfigurational perturbation theory, Phys. Chem. Chem. Phys. 11 (2009) 2631-2639, https://doi.org/10.1039/B820646E.

[50] J. Soto, M. Algarra, Insights into the Thermal and Photochemical Reaction Mechanisms of Azidoacetonitrile. Spectroscopic and MS-CASPT2 Calculations, ChemPhysChem. 21 (2020) 1126-1133, https://doi.org/10.1002/ cphc. 202000201.

[51] G. Schaftenaar, J.H. Noordik, Molden: a pre- and post-processing program for molecular and electronic structures, J. Comput.-Aided Mol. Des. 14 (2000) 123-134, https://doi.org/10.1023/A:1008193805436.

[52] B.M. Bode, M.S. Gordon, Macmolplt: a graphical user interface for GAMESS, J. Molec. Graph. Modell. 16 (1998) 133-138, https://doi.org/10.1016/S10933263(99)00002-9.

[53] M. Algarra, M. Pérez-Martín, M. Cifuentes-Rueda, J. Jiménez-Jiménez, J.C.G. Esteves da Silva, T.J. Bandosz, E. Rodríguez-Castellón, J.T. López-Navarrete, J. Casado, Carbon Dots obtained using hydrothermal treatment of formaldehyde. Cell imaging in-vitro, Nanoscale 15 (2014) 9071-9077, https://doi.org/ 10.1039/C4NR01585A.

[54] https://magritek.com/2017/06/14/13c-nmr-of-cholesterol-on-an-80-MHzmagnet/

[55] J. F Moulder, W.F. Stickle, P.E. Sobol, K.D. Bomben. In: Handbook of X Ray Photoelectron Spectroscopy: A reference book of standard spectra for identification and interpretation of XPS Data, Physical Electronics, Eden Prairie, Minn., 1995.

[56] I. Milenković, M. Algarra, C. Alcoholado, M. Cifuentes, J.M. Lázaro-Martínez, E. Rodríguez-Castellón, D. Mutavdžić, K. Radotić, T.J. Bandosz, Fingerprint imaging using N-doped carbon dots, Carbon 144 (2019) 791-797, https:// doi.org/10.1016/j.carbon.2018.12.102.

[57] M. Petković, J. Schiller, M. Müller, S. Benard, S. Reichl, K. Arnold, J. Arnhold, Detection of Individual Phospholipids in Lipid Mixtures by Matrix-Assisted Laser Desorption/Ionization Time-of-Flight Mass Spectrometry: Phosphatidylcholine Prevents the Detection of Further Species, Anal. Biochem. 289 (2001) 202-216, https://doi.org/10.1006/abio.2000.4926.

[58] J. Schiller, J. Arnhold, S. Benard, M. Müller, S. Reichl, K. Arnold, Lipid Analysis by Matrix-Assisted Laser Desorption, and Ionization Mass Spectrometry: A Methodological Approach, Anal. Biochem. 267 (1999) 46-56, https://doi.org/ 10.1006/abio.1998.3001.

[59] M. Popović, M. Nešić, Nišavić, M. Vranješ, T. Radetić, Z. Šaponjić, R. Masnikosa, M. Petković, Suitability of TiO2 nanoparticles and prolate nano-spheroids for laser desorption/ionization mass spectrometric characterization of bipyridinecontaining complexes, Mater. Lett. 150 (2015) 84-88, https://doi.org/10.1016/ j.matlet.2015.03.004.

[60] K.M. McAvey, B. Guan, C.A. Fortier, M.A. Tarr, R.B. Cole, Laser-Induced Oxidation of Cholesterol Observed During MALDI-TOF Mass Spectrometry, J. Am. Soc. Mass Spectrom. 22 (2011) 659-669, https://doi.org/10.1007/s13361011-0074-3.

[61] M.J García, A.M. Cell volume variation under different concentrations of saline solution Rev. Colomb. Anestesiol. 37 (2009) 106-109).

[62] M. Louleb, L. Latrous, A. Ríos, M. Zougagh, E. Rodríguez-Castelloń, M. Algarra, J. Soto, Detection of Dopamine in Human Fluids Using N-Doped Carbon Dots, ACS Appl. Nano Mater. 3 (2020) 8004-8011, https://doi.org/10.1021/ acsanm.0c01461.

[63] M. Algarra, V. Moreno, J.M. Lázaro-Martínez, E. Rodríguez-Castellón, J. Soto, J. Morales, A. Benítez, Insights into the formation of $\mathrm{N}$ doped 3D-graphene quantum dots. Spectroscopic and computational approach, J. Coll. Interf. Sci. 561 (2020) 678-686, https://doi.org/10.1016/j.jcis.2019.11.044.

[64] A. Fernández-Ramos, J. Rodríguez-Otero, M.A. Ríos, J. Soto, Intramolecularproton transfer in 2-(2'-hydroxyphenyl)benzoxazole: the reliability of ab initio calculations on simplified structures, J. Mol. Struct. THEOCHEM 489 (1999) 255-262, https://doi.org/10.1016/S0166-1280(99) 00062-7.

[65] T. Clark, J.S. Murray, P. Politzer, A perspective on quantum mechanics and chemical concepts in describing noncovalent interactions, Phys. Chem. Chem. Phys. 20 (2018) 30076-30082, https://doi.org/10.1039/C8CP06786D. 